\title{
POROUS METAL OXIDE-CARBON COMPOSITE WITH HOLLOW STRUCTURE FOR ENERGY STORAGE APPLICATIONS
}

\author{
Surya Prasad Adhikari ${ }^{* 1}$
}

\begin{abstract}
Nanocomposite structure of porous hollow $\mathrm{TiO}_{2}$ nanofibers (NFs) and graphitic carbon nitride $\left(\mathrm{g}-\mathrm{C}_{3} \mathrm{~N}_{4}\right)$ sheets were directly fabricated by means of a novel electrospinning combined with calcination process. Owing to the high porosity, these nanostructured demonstrate enhanced energy storage properties when used in supercapacitors (SCs). Nanomaterials in particular offer unique properties or combinations of properties as electrodes and electrolytes in a range of energy devices. The energy storage behavior of electrochemical capacitors (ECs) made from $\mathrm{TiO}_{2} / \mathrm{g}$ $\mathrm{C}_{3} \mathrm{~N}_{4}$ nanocomposites was investigated by cyclic voltammetry and electrochemical impedance spectra. These tests showed that the supercapacitive performance of g- $\mathrm{C}_{3} \mathrm{~N}_{4}$ was significantly enhanced after attaching porous $\mathrm{TiO}_{2}$ nanofibers.
\end{abstract}

Keywords: Electrospinning, $\mathrm{g}_{-} \mathrm{C}_{3} \mathrm{~N}_{4}$, Porous $\mathrm{TiO}_{2} \mathrm{NFS}$, Supercapacitors

\section{INTRODUCTION}

Because of the dazzling advantages of SCs, such as short operating time of charge and discharge, long cycle life, relatively high energy density, and power density devices, SCs are replacing environmentally harmful fuels in more and more fields [1, 2] . However, some shortcomings still need to be solved including the high cost, instability and low energy density; the key to solving these problems is the electrode materials [3]. SCs are prepared from carbon-based materials including activated carbon, carbide derived carbon, zeolite-templated carbon, carbon aerogel, carbon nanotube, onion-like carbon, carbon fiber, grapheme and graphitic carbon nitride $\left(\mathrm{g}-\mathrm{C}_{3} \mathrm{~N}_{4}\right)$ [4-6]. Among these materials, Graphitic carbon nitride (g-C3N4), a polymeric, metal-free, non toxic, earth-abundant and visible light driven semiconductor with a mild band gap $(2.7 \mathrm{eV})$ has become hot-spot in various scientific exploits such as environmental pollution mitigation, energy generation and storage, organic synthesis, sensors, etc due to the tri-s-triazine units that are connected by amino groups in each layer and the weak van der waals forces between layers [3, 7]. Most of the published article can be found mainly focusing on catalytic applications of g- $\mathrm{C}_{3} \mathrm{~N}_{4}$. However, a systematic description of the energy-related applications such as batteries, SCs, white-light-emitting diodes, and oxygen reduction reaction of $\mathrm{g}_{-} \mathrm{C}_{3} \mathrm{~N}_{4}$ has not been presented until now. The presence of nitrogen atoms in the graphene-like layered g- $\mathrm{C}_{3} \mathrm{~N}_{4}$ structure gives high supercapacitive performance with better performance than graphene in some aspect $[8,9]$. However, the supercapacitive efficiency of $g_{-} \mathrm{C}_{3} \mathrm{~N}_{4}$ alone is still low due to its lower practical surface area. So, various techniques have been adopted

Department of Automobile \& Mechanical Engineering

Thapathali Campus, Institute of Engineering, Nepal

Corresponding author

E-mail : surya@tcioe.edu.np 
to improve its capacitive efficiency. The fabrication of composite materials with other semiconductors, doping with noble metals and non-metals are worth mentioning [10-12].

Metal oxides such as nickel oxide, cobalt oxide, zinc oxide, titanium oxide and manganese oxide etc., have been used widely in SCs because of its high specific capacitance and prominent electrochemical properties. Among these, $\mathrm{TiO}_{2}$ has found to be a gifted and competent metal oxide because of its considerable advantages such as low cost, chemically stable, natural abundance, low toxicity, environmentally friendly nature, good dielectric materials and faradic capacitance [13, 14]. It has wide application, such as, catalysis, ionsieves, rechargeable batteries, chemical sensing devices, magnetic devices, field-emission devices, hydrogen storage media, electrochemical capacitors and microelectronics. [15-19].

The merged $\mathrm{TiO}_{2}$ with $\mathrm{g}-\mathrm{C}_{3} \mathrm{~N}_{4}$ sheets has expected to form a composite material with high capacitance from the above mention articles. The practical applications of any composites depend on the morphology. Therefore $\mathrm{TiO}_{2} / \mathrm{g}-\mathrm{C}_{3} \mathrm{~N}_{4}$ composite is also unalterably depending on the morphology of these two materials. The biggest challenge is to control the structure of these composites. Previous literature has reported that the sheet-like structures of g- $\mathrm{C}_{3} \mathrm{~N}_{4}$-based composites exhibit distinctive optical and electronics properties compared to bulk g- $\mathrm{C}_{3} \mathrm{~N}_{4}$ composites [20]. Similarly, among various $\mathrm{TiO}_{2}$ nanostructures, the onedimensional $\mathrm{TiO}_{2}$ NFs or nanorods attracted serious interest in view of the dimensional confinement and minimal agglomeration compared to nanoparticles (NPs) [21]. Therefore, bearing in mind the above mentioned observations, it is to be predicted that a composite made of sheet-like $\mathrm{g}_{-} \mathrm{C}_{3} \mathrm{~N}_{4}$ and porous $\mathrm{TiO}_{2} \mathrm{NFs}$ will exhibit encouraging properties, tending toward-enhanced electrochemical properties. So, I am inspired to develop a simple technique for creating such a composite material. To the best of my knowledge, there has been no report on the fabrication of one dimensional porous $\mathrm{TiO}_{2} \mathrm{NFs}$ grafted onto $\mathrm{g}-\mathrm{C}_{3} \mathrm{~N}_{4}$ sheets. Recently, Han C. et al. synthesized a composite of $\mathrm{TiO}_{2} \mathrm{NFs}$ and $\mathrm{g}-\mathrm{C}_{3} \mathrm{~N}_{4}$ sheets by electrospinning, in which $\mathrm{g}-\mathrm{C}_{3} \mathrm{~N}_{4}$ was embedded inside the NFs [22]. But, in this study, for the first time, $\mathrm{TiO}_{2}$ porous NFs-having sufficient length were dispersed homogeneously and attached on the surfaces of $\mathrm{g}-\mathrm{C}_{3} \mathrm{~N}_{4}$ sheet with minimal agglomeration of NFs from an angled two-nozzle electrospinning process with calcination. Here, the massive surface area of $\mathrm{g}_{-} \mathrm{C}_{3} \mathrm{~N}_{4}$ sheets provides satisfactory surfaces for the direct attachment of $\mathrm{TiO}_{2} \mathrm{NFs}$, which make charge separation more efficient. Such NFs have a better chance than NPs to be uniformly attached onto $\mathrm{g}-\mathrm{C}_{3} \mathrm{~N}_{4}$ sheets to form bonding, simply based on geometric considerations. Thus, the prepared composite of $\mathrm{TiO} 2 / \mathrm{g}-\mathrm{C}_{3} \mathrm{~N}_{4}$ demonstrated higher electrochemical capacitive behavior than pure $\mathrm{TiO}_{2}$ and $\mathrm{g}-\mathrm{C}_{3} \mathrm{~N}_{4}$. This method provides a facile and straightforward approach for affixing porous $\mathrm{TiO}_{2} \mathrm{NFs}$ on the surface of $\mathrm{g}-\mathrm{C}_{3} \mathrm{~N}_{4}$ sheets from a simple and low cost electrospinning process.

\section{EXPERIMENTAL}

\section{Materials}

Commercially available $\mathrm{g}-\mathrm{C}_{3} \mathrm{~N}_{4}$ particles nicanite ${ }^{\circledR}$, (Carbedon, Finland), acetic acid, titanium isopropoxide (TTIP), polyvinyl acetate (PVAc, $\mathrm{Mw}=500000$ ) and N,N- 
Dimethylformamide (DMF) were purchased from Sigma Aldrich and used as-received.

\section{Fabrication of $\mathrm{TiO}_{2}$ NFs-intercalated g- $\mathrm{C}_{3} \mathrm{~N}_{4}$ sheets}

Here, $\mathrm{TiO}_{2} / \mathrm{g}-\mathrm{C}_{3} \mathrm{~N}_{4}$ hybrid composite was directly prepared by using an angled two-nozzle electrospinning-calcination process. Typically, two different solutions, one containing g- $\mathrm{C}_{3} \mathrm{~N}_{4}$ and the other containing $\mathrm{TiO}_{2}$ precursors were made from the same polymer solution. First, PVAc solution (18 wt \%) in DMF was prepared by overnight magnetic stirring at room temperature. Thereafter, $\mathrm{g}_{-} \mathrm{C}_{3} \mathrm{~N}_{4}$ particles $(1,3,5$ and $10 \mathrm{wt} \%$ with respect to the weight of the PVAc) were added to the PVAc solution and the mixture was subjected to bath sonication for two hours, to disperse the $\mathrm{g}-\mathrm{C}_{3} \mathrm{~N}_{4}$ particles. Similarly, the $\mathrm{TiO}_{2}$ precursor-containing PVAc solution was prepared by mixing $6 \mathrm{~g}$ of the PVAc solution and $5 \mathrm{~g}$ of clear solution of TTIP (obtained by dropwise addition of acetic acid with continuous stirring). For two-nozzle electrospinning, one syringe contained PVAc solution with $\mathrm{g}-\mathrm{C}_{3} \mathrm{~N}_{4}$ particles while the other contained PVAc solution with $\mathrm{TiO}_{2}$ precursors. The angle between the two nozzle tips was maintained at $80^{\circ}$. A schematic diagram for the preparation of the composite is as shown in Figure 1. Electrospinning was carried out in room conditions where the parameters include $18 \mathrm{kV}$ of applied voltage, a tip-to-collector distance of $12 \mathrm{~cm}$, and solution feed rate of $1 \mathrm{ml} / \mathrm{h}$. The obtained electrospun mats were vacuum dried at $80{ }^{\circ} \mathrm{C}$ overnight. Then the vacuum-dried electrospun mats were treated in air at $500{ }^{\circ} \mathrm{C}$ for $3 \mathrm{~h}$ at the heating rate of $5{ }^{\circ} \mathrm{C} / \mathrm{min}$. At such a high temperature, TTIP [Ti $\left\{\mathrm{OCH}(\mathrm{CH}]\right.$ molecules could decompose into $\mathrm{TiO}_{2}, \mathrm{CO}_{2}$ and $\mathrm{H}_{2} \mathrm{O}$. Here, $\mathrm{CO}_{2}$ and $\mathrm{H}_{2} \mathrm{O}$ escaped rapidly, and only $\mathrm{TiO}_{2}$ and $\mathrm{g}_{-} \mathrm{C}_{3} \mathrm{~N}_{4}$ sheets remained. At high temperature, $\mathrm{TiO}_{2}$ molecules could react and generate anatase/rutile- $\mathrm{TiO}_{2}$. Here, the composite material in which $\mathrm{TiO}_{2}$ NFs attached on the surface of the $\mathrm{g}-\mathrm{C}_{3} \mathrm{~N}_{4}$ sheets are denoted as "TCN-x", where, "TCN" refers $\mathrm{TiO}_{2} / \mathrm{g}-\mathrm{C}_{3} \mathrm{~N}_{4}$ composite and $\mathrm{x}$ refers the wt $\%$ of $\mathrm{g}-\mathrm{C}_{3} \mathrm{~N}_{4}$ w.r.t. the polymer weight, namely $1,3,5$ and 10 . Note that the mass ratio of $g_{-} \mathrm{C}_{3} \mathrm{~N}_{4}$ sheet affects the spinnability of the solution. Above $10 \mathrm{wt} \%$ of $\mathrm{g}-\mathrm{C}_{3} \mathrm{~N}_{4}$ sheet, spinnability diminishes and it is difficult to obtain fibers due to the increasing viscosity. Moreover, pristine $\mathrm{TiO}_{2}$ NFs were prepared the same as $\mathrm{TiO}_{2} / g-\mathrm{C}_{3} \mathrm{~N}_{4}$ from the solution containing $\mathrm{TiO}_{2}$ precursors, using a single-nozzle electrospinning process with all conditions identical to that of the two-nozzle electrospinning.

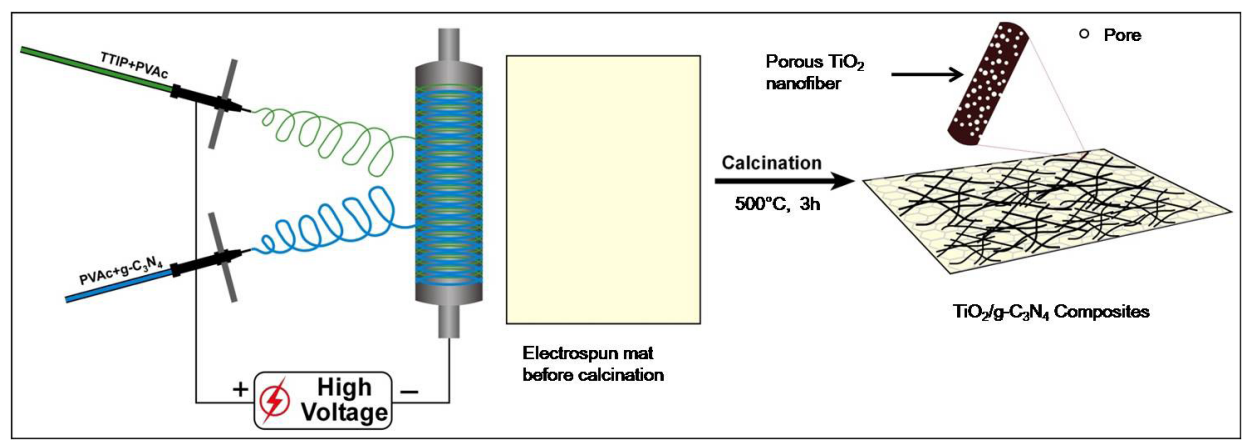

Figure 1: Schematic illustration for the synthesis of the $\mathrm{TiO}_{2} / \mathrm{g}-\mathrm{C}_{3} \mathrm{~N}_{4}$ composite. 


\section{Electrochemical measurements}

The cyclic voltammograms $(\mathrm{CV})$ were taken in an $\mathrm{N}_{2}$-saturated $0.01 \mathrm{M}$ potassium ferrocyanide solution prepared with $1 \mathrm{M} \mathrm{KNO}_{3}$, with the scanning rate $50 \mathrm{mV} / \mathrm{s}$ on a Potentiostat/Galvanostat/EIS (WonTech, ZIVE, SPI Korea) that was equipped with three-electrode system. A platinum electrode, $1.6 \mathrm{~mm}$ in diameter and coated with the asprepared catalyst paste was used as the working electrode. A standard calomel electrode was used as the reference electrode and platinum wire was used as the counter electrode. Similarly, electrochemical impedance spectra (EIS) Nyquist plots measurements were taken in the same system over the frequency range of 0.001 to $100 \mathrm{kHz}$. Before measurement, the working electrode was prepared as follows: $20 \mathrm{mg}$ of the different asprepared samples were added to $20 \mu \mathrm{L}$ of a solution of Nafion (5 wt \%) and propanol. Subsequently, ultrasonication was carried out for $1 \mathrm{~h}$ to obtain a homogeneous paste. Then $5 \mu \mathrm{g}$ of the paste was taken and dripped on the surface of the platinum electrode to form a thin catalyst film on the electrode. After drying at $80{ }^{\circ} \mathrm{C}$ in an oven for $30 \mathrm{~min}$, the working electrode was used for experiments.

\section{RESULTS AND DISCUSSION}

\section{Characterization of the composite}

The morphologies of the prepared samples are observed by FE-SEM. It was found that TTIP/PVAc composite electrospun NFs are uniform with smooth surfaces before calcination (Figure 3a). It can be observed from the figure that the $\mathrm{TiO}_{2} \mathrm{NFs}$ remained as continuous structures with uniform diameters after calcinations. However, their average diameter was decreased slightly (Figure 3b). Furthermore, in the composite electrospun mat with $\mathrm{g}-\mathrm{C}_{3} \mathrm{~N}_{4}$ sheet, fibers with two different diameters can be distinguished; the larger-diameter fibers are the fibers of $\mathrm{g}-\mathrm{C}_{3} \mathrm{~N}_{4} / \mathrm{PVAc}$; the smaller-diameter fibers are the fibers of TTIP/PVAc, as demonstrated in Figure 3c. It is noticeable on the FE-SEM image that the $\mathrm{TiO}_{2} \mathrm{NFs}$ are affixed on the $\mathrm{g}-\mathrm{C}_{3} \mathrm{~N}_{4}$ sheet after calcination in a reasonably unvarying manner (Figure 3d). The attached NFs have a length of several micrometers with porous structure, but the diameter varies from $40 \mathrm{~nm}$ up to $150 \mathrm{~nm}$. In contrast to the NPs, such NFs of significant length promote direct and sufficient contact with $\mathrm{g}-\mathrm{C}_{3} \mathrm{~N}_{4}$ sheet, resulting in less agglomeration, hence, further enhancing the photodegradation efficiency. Moreover, such a very thin sheet, having large aspect ratios, high surface area and a stoichiometric $\mathrm{N} / \mathrm{C}$ ratio, increase the transport of charges and reduce the recombination probability of photoexcited charge carriers. 


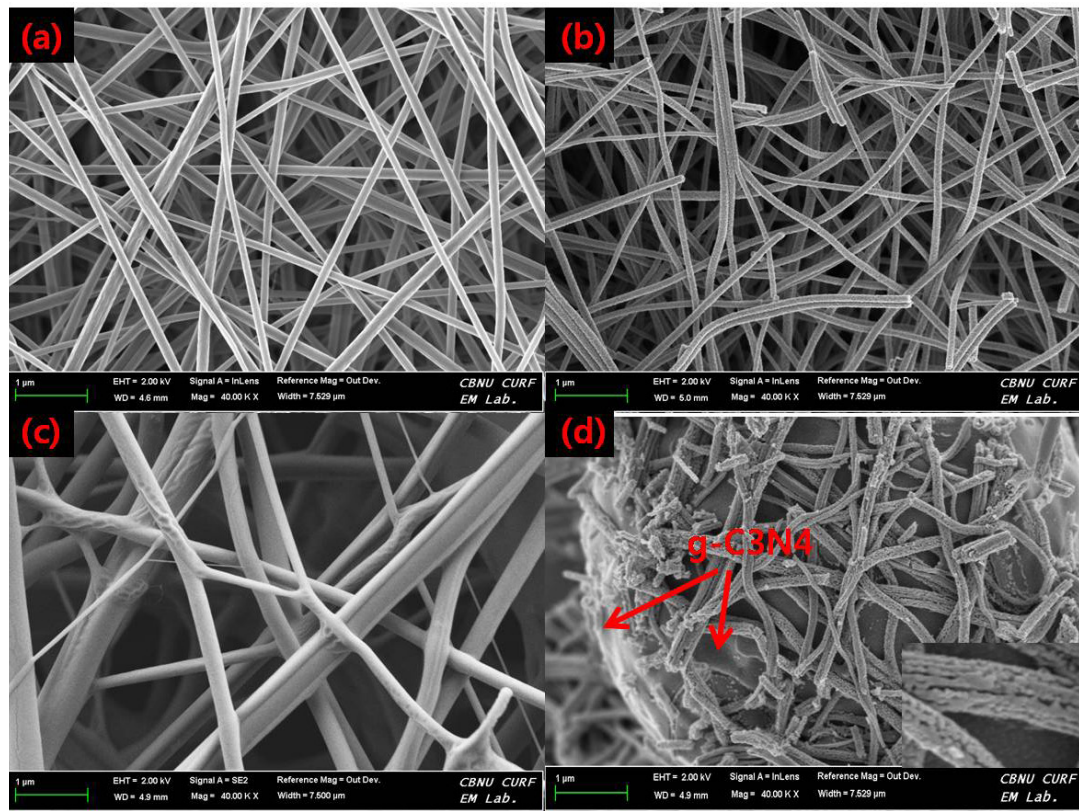

Figure 2: FE-SEM images of (a) TTIP/PVAC fibers before calcination, (b) $\mathrm{TiO}_{2}$ fibers after calcination, (c) TTIP/PVAC/g- $\mathrm{C}_{3} \mathrm{~N}_{4}$ fibers before calcination, and (d) TCN composite after calcinations (inset of figure d shows the porous structure of $\mathrm{TiO}_{2} \mathrm{NFs}$ ). The XPS survey spectrum and high resolution spectrum of the pristine and composite samples were carried out to further illuminate the surface composition and chemical interaction between the elements. Figure $3 \mathrm{a}$ illustrates the XPS survey spectrum of g- $\mathrm{C}_{3} \mathrm{~N}_{4}, \mathrm{TiO}_{2}$ and TCN. Obviously, the $\mathrm{g}-\mathrm{C}_{3} \mathrm{~N}_{4}$ contains the photoelectron peaks of $\mathrm{C}$ and $\mathrm{N}$ elements, and TCN-5 composite contains the photoelectron peaks of $\mathrm{C}, \mathrm{N}, \mathrm{Ti}$ and $\mathrm{O}$ elements. However, the pure $\mathrm{TiO}_{2} \mathrm{NFs}$ not only contain the photoelectron peaks of $\mathrm{Ti}$ and $\mathrm{O}$ elements, but also contains the peak of $\mathrm{C}$ elements. This carbon peak is ascribed to the residual carbon from the samples and adventitious hydrocarbon from the XPS instrument itself. The deconvoluted peaks of all elements of the composite material are given in the corresponding high-resolution spectrum (Figure 3b-3e). The $\mathrm{C} 1 \mathrm{~s}$ peak of composite can be deconvoluted two fitted peaks at $285.65 \mathrm{eV}$ and $287.05 \mathrm{eV}$ (Figure $3 \mathrm{~b}$ ) indicating that carbon posses two diverse chemical states [23]. The peak around $285.65 \mathrm{eV}$ is attributed to defects in the $\mathrm{g}_{-} \mathrm{C}_{3} \mathrm{~N}_{4}$ that involves $\mathrm{sp}^{2}$-hybridized carbon atoms. In addition, the other peak located around $287.05 \mathrm{eV}$ is assigned to $\mathrm{N}-\mathrm{C}=\mathrm{N}$ coordination $[24,25]$. The curves of $\mathrm{N} 1 \mathrm{~s}$ region can be divided also into two peaks situated at $397.7 \mathrm{eV}$ and $399.8 \mathrm{eV}$ (Figure 3c). The main peak located at $397.7 \mathrm{eV}$ belong to $\mathrm{sp} 2$-hybridized pyridinic-like nitrogen $\left(\mathrm{N}-\mathrm{sp}^{2} \mathrm{C}\right)$ and the peak located at $399.8 \mathrm{eV}$ corresponds to the tertiary pyrrolic graphitic nitrogen $\left(\mathrm{N}-(\mathrm{C})_{3}\right)$ [26]. The Ti $2 \mathrm{p}_{3 / 2}$ spin-orbital splitting photoelectron of the composite was located at binding energy $459.5 \mathrm{eV}$ in the Ti $2 \mathrm{p}$ spectrum. Similarly, peaks at $465.05 \mathrm{eV}$ in the same spectrum correspond to the Ti $2 \mathrm{p}_{1 / 2}$ (Figure $3 \mathrm{~d}$ ) [27]. The peak situated at $530.65 \mathrm{eV}$ in the $\mathrm{O} 1 \mathrm{~s}$ is ascribable to oxygen anions in the lattice (Ti-O) 
(Figure 3e) [28]. Furthermore, the binding energy values of Ti $2 p$ in the composite are slightly higher than those of pristine $\mathrm{TiO}_{2}$ (Figure 3f) [29]. Hence, the results from FESEM and XPS analyses strongly verified that the $\mathrm{TiO}_{2} \mathrm{NFs}$ are attached on the surface of g- $\mathrm{C}_{3} \mathrm{~N}_{4}$ sheets forming a hetero-structure rather than a physical mixture.
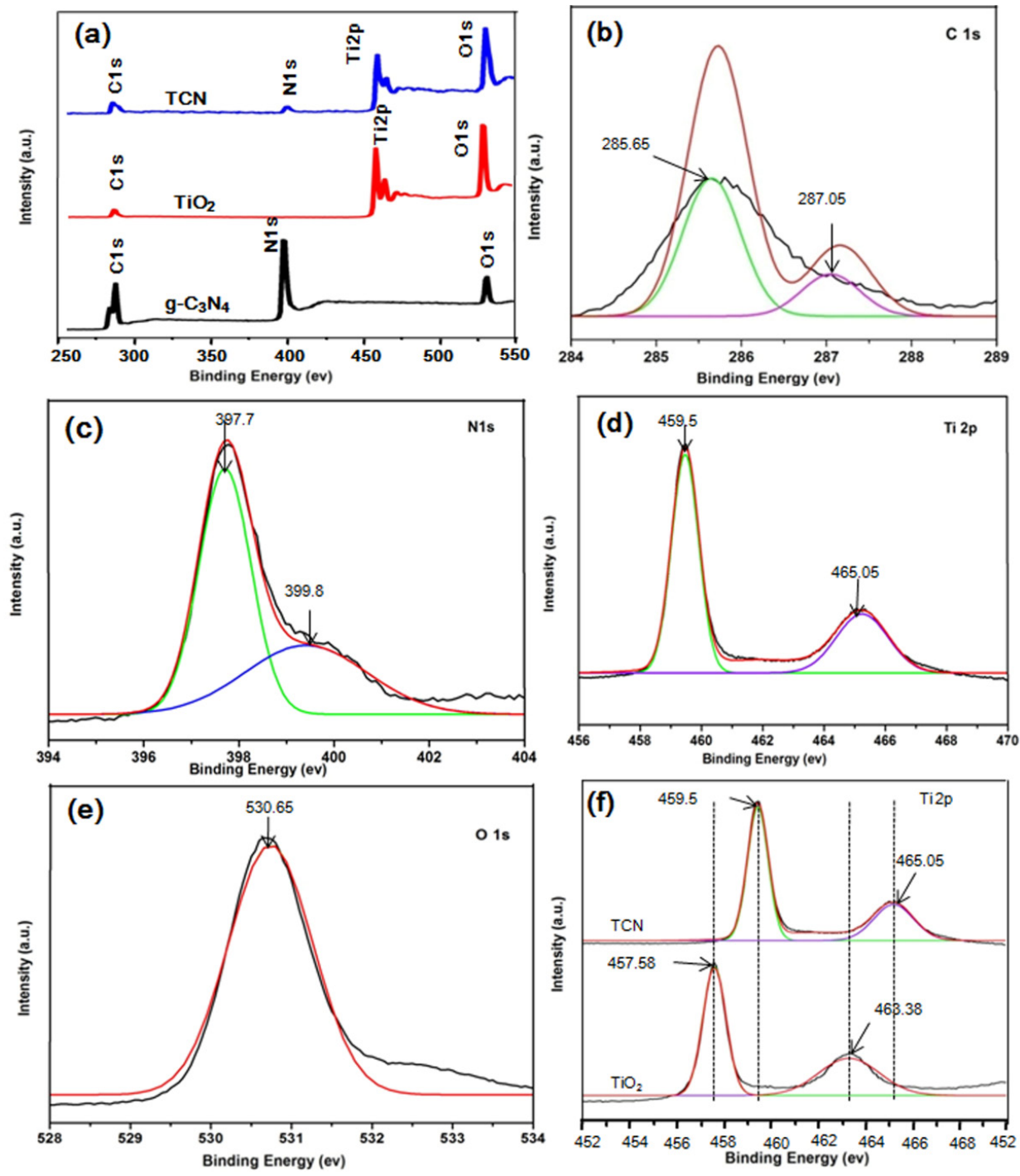

Figure 3: (a) XPS survey spectrum and high resolution XPS spectra of (b) C1s, (c) N1s, (d) Ti 2p, (e) O1s and (f) shifting of Ti2p peak in TCN-5 composite.

To analyze the electrochemical capacitive performance, a potentiostat/galvanostat/EIS analyzer was used to measure the $\mathrm{CV}$ to confirm the interfacial charge transfer effect of $\mathrm{TiO}_{2}, \mathrm{~g}-\mathrm{C}_{3} \mathrm{~N}_{4}$ and TCN-5. Figure 4 reveals $\mathrm{CV}$ of different samples, in which clearer reduction and oxidation peaks are observed for TCN-5 than other two pristine samples. As shown in the figure, the oxidation peaks for $\mathrm{g}_{-} \mathrm{C}_{3} \mathrm{~N}_{4}, \mathrm{TiO}_{2}$ and TCN-5 are located at 
$0.45,0.57$ and $0.27 \mathrm{~V}$ and respectively represent the oxidation of ferrocyanide with the loss of one electron. The peak current of TCN-5 $\left(0.127 \mathrm{~mA} / \mathrm{cm}^{2}\right)$ is much higher than that of $\mathrm{g}-\mathrm{C}_{3} \mathrm{~N}_{4}\left(0.0505 \mathrm{~mA} / \mathrm{cm}^{2}\right)$ and $\mathrm{TiO}_{2}\left(0.039 \mathrm{~mA} / \mathrm{cm}^{2}\right)$-more than 2.5 times, signifying a considerably improved the capacitive performance. Furthermore, the ratio of the strengths of the oxidation $\left(0.127 \mathrm{~mA} / \mathrm{cm}^{2}, 0.29 \mathrm{~V}\right)$ and reduction peaks $\left(0.112 \mathrm{~mA} / \mathrm{cm}^{2}, 0.15 \mathrm{~V}\right)$ of TCN-5 is nearly 1 , which specifying greatly enhanced reaction reversibility. The electrode capacitance depends on the $\mathrm{CV}$ curve area, scan rate, material amount and applied potential range. Here, TCN-5 has the highest specific area among the others, so the composite of $\mathrm{TiO}_{2}$ and $\mathrm{g}-\mathrm{C}_{3} \mathrm{~N}_{4}$ electrode give the highest specific capacitance. EIS Nyquist plots were also recorded to further investigate the interfacial charge immigration of the samples (Fig.5). It has been reported in recent research that a smaller arc radius in Nyquist plots are related to a more effective interfacial charge immigration in semiconductor based electrode [30]. Arc radius for TCN-5 in the Nyquist plot (Figure 13) is smaller compared to $\mathrm{g}-\mathrm{C}_{3} \mathrm{~N}_{4}$ and $\mathrm{TiO}_{2}$, demonstrating the reduced interface resistance so that the capacitive performance will be enhanced. Thus, combine with CV measurements and EIS Nyquist plots, it is concluded that the $\mathrm{g}-\mathrm{C}_{3} \mathrm{~N}_{4}$ sheet modified by porous $\mathrm{TiO}_{2} \mathrm{NFs}$ exhibits the enhanced capacitive performance compared to ones.

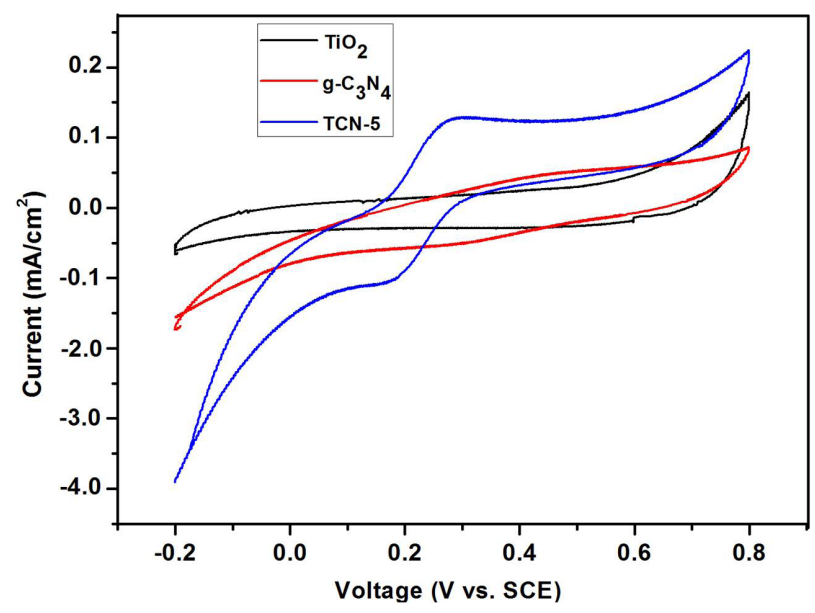

Figure 4: Cyclic voltammograms of $\mathrm{TiO}_{2}, \mathrm{~g}_{-} \mathrm{C}_{3} \mathrm{~N}_{4}$ and $\mathrm{TCN}-5$ 


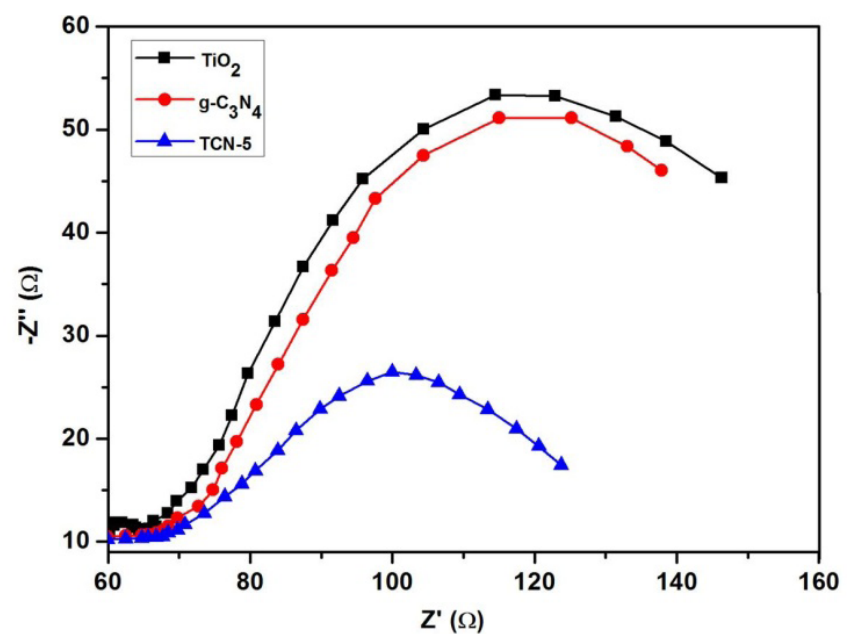

Figure 5: Electrochemical impedance spectra of $\mathrm{TiO}_{2}, \mathrm{~g}-\mathrm{C}_{3} \mathrm{~N}_{4}$ and $\mathrm{TCN}-5$

\section{Conclusions}

In conclusion, we display a new technique to synthesize $\mathrm{TiO}_{2}$ porous hollow NFs well attached to the surface of the sheet-like structure of $\mathrm{g}-\mathrm{C}_{3} \mathrm{~N}_{4}$ through the use of a simple and facile two nozzle electrospinning process followed by calcination process. Because of the hierarchical porous structure, the composite has relatively large specific surface area. The CV and EIS Nyquist plots measurements showed that, after incorporation of porous $\mathrm{TiO}_{2}$ NFs, the composites exhibited significantly enhanced electrochemical capacitive performance compared to pristine $\mathrm{TiO}_{2}$ and $\mathrm{g}-\mathrm{C}_{3} \mathrm{~N}_{4}$. Here the hollow one dimensional porous structure attached on the $\mathrm{g}-\mathrm{C}_{3} \mathrm{~N}_{4}$ sheet play an important role to enhance the capacitive performances of composite.

\section{Acknowledgement}

This research was supported by research fund of Chonbuk National University in 2014 and by grants from the Korean Ministry of Education, Science, and Technology (MEST) through the National Research Foundation (NRF) (Project no: 2014-R1A1A2009068)2

[1] E. Conway B. Transition From Supercapacitor to Battery Behaviour in Electrochemical EnergyStorage1991.

[2] Jiang H, Lee PS, Li C. 3D carbon based nanostructures for advanced supercapacitors. Energy \& Environmental Science 2013;6:41-53.

[3] Li Y, Xu X, He Y, Jiang Y, Lin K. Nitrogen Doped Macroporous Carbon as Electrode Materials for High Capacity of Supercapacitor2017.

[4] Pagketanang T, Artnaseaw A, Wongwicha P, Thabuot M. Microporous Activated Carbon from KOH-Activation of Rubber Seed-Shells for Application in Capacitor Electrode. Energy Procedia 2015;79:651-6.

[5] Zhou S-X, Tao X-Y, Ma J, Guo L-T, Zhu Y-B, Fan H-L, et al. Synthesis of flower-like PANI/g-C3N4 nanocomposite as supercapacitor electrode. Vacuum 2018;149:175-9.

[6] Abstracts. Fuel and Energy Abstracts 2014;55:2-98.

[7] Hou Y, Wen Z, Cui S, Feng X, Chen J. Strongly Coupled Ternary Hybrid Aerogels of N-deficient Porous Graphitic-C3N4 Nanosheets/N-Doped Graphene/NiFe-Layered Double Hydroxide for Solar-Driven Photoelectrochemical Water Oxidation. Nano Letters 2016;16:2268-77.

[8] LiZ, Wu L, Wang L, Gu A, Zhou Q. Nickel cobalt sulfide nanosheets uniformly anchored on porous graphitic carbon nitride for supercapacitors with high cycling performance. Electrochimica Acta 
2017;231:617-25.

[9] Tang L, Jia C-t, Xue Y-c, Li L, Wang A-q, Xu G, et al. Fabrication of compressible and recyclable macroscopic g-C3N4/GO aerogel hybrids for visible-light harvesting: A promising strategy for water remediation. Applied Catalysis B: Environmental 2017;219:241-8.

[10] Hou Y, Li J, Wen Z, Cui S, Yuan C, Chen J. N-doped graphene/porous g-C3N4 nanosheets supported layered-MoS2 hybrid as robust anode materials for lithium-ion batteries. Nano Energy 2014;8:157-64.

[11] Mamba G, Mishra AK. Graphitic carbon nitride ( $g$-C3N4) nanocomposites: A new and exciting generation of visible light driven photocatalysts for environmental pollution remediation. Applied Catalysis B: Environmental 2016;198:347-77.

[12] Shi L, Zhang J, Liu H, Que M, Cai X, Tan S, et al. Flower-like Ni(OH)2 hybridized g-C3N4 for high-performance supercapacitor electrode material. Materials Letters 2015;145:150-3.

[13] Su C, Hong BY, Tseng CM. Sol-gel preparation and photocatalysis of titanium dioxide. Catalysis Today 2004;96:119-26.

[14] Nitnithiphrut P, Thabuot M, Seithtanabutara V. Fabrication of Composite Supercapacitor Containing Para Wood-derived Activated Carbon and TiO2. Energy Procedia 2017;138:116-21.

[15] Ren L, Li Y, Hou J, Zhao X, Pan C. Preparation and Enhanced Photocatalytic Activity of TiO2 Nanocrystals with Internal Pores. ACS Applied Materials \& Interfaces 2014;6:1608-15.

[16] Height MJ, Pratsinis SE, Mekasuwandumrong O, Praserthdam P. Ag-ZnO catalysts for UVphotodegradation of methylene blue. Applied Catalysis B: Environmental 2006;63:305-12.

[17] Zhang Y, Zhang N, Tang Z-R, Xu Y-J. Graphene Transforms Wide Band Gap ZnS to a Visible Light Photocatalyst. The New Role of Graphene as a Macromolecular Photosensitizer. ACS Nano 2012;6:9777-89.

[18] Lио M, Liи Y, Ни J, Liu H, Li J. One-Pot Synthesis of CdS and Ni-Doped CdS Hollow Spheres with Enhanced Photocatalytic Activity and Durability. ACS Applied Materials \& Interfaces 2012;4:1813-21.

[19] Sayama K, Hayashi H, Arai T, Yanagida M, Gunji T, Sugihara H. Highly active WO3 semiconductor photocatalyst prepared from amorphous peroxo-tungstic acid for the degradation of various organic compounds. Applied Catalysis B: Environmental 2010;94:150-7.

[20] Niи P, Zhang L, Liu G, Cheng H-M. Graphene-Like Carbon Nitride Nanosheets for Improved Photocatalytic Activities. Advanced Functional Materials 2012;22:4763-70.

[21] Pan X, Zhao Y, Liu S, Korzeniewski CL, Wang S, Fan Z. Comparing Graphene-TiO2 Nanowire and Graphene-TiO2 Nanoparticle Composite Photocatalysts. ACS Applied Materials \& Interfaces 2012;4:3944-50.

[22] Han C, Wang $Y$, Lei $Y$, Wang B, Wu N, Shi Q, et al. In situ synthesis of graphitic-C3N4 nanosheet hybridized $\mathrm{N}$-doped TiO2 nanofibers for efficient photocatalytic $\mathrm{H} 2$ production and degradation. Nano Res 2015;8:1199-209.

[23] Ng J, Wang X, Sun DD. One-pot hydrothermal synthesis of a hierarchical nanofungus-like anatase TiO2 thin film for photocatalytic oxidation of bisphenol A. Applied Catalysis B: Environmental 2011;110:260-72.

[24] Liu B, Zeng HC. Carbon Nanotubes Supported Mesoporous Mesocrystals of Anatase TiO2. Chemistry of Materials 2008;20:2711-8.

[25] Chai B, Peng T, Zhang X, Mao J, Li K, Zhang X. Synthesis of C60-Decorated SWCNTs (C60-dCNTs) and Its TiO2-Based Nanocomposite with Enhanced Photocatalytic Activity for Hydrogen Production2012.

[26] Huang Za, Sun Q, Lv K, Zhang Z, Li M, Li B. Effect of contact interface between TiO2 and g-C3N4 on the photoreactivity of g-C3N4/TiO2 photocatalyst: (001) vs (101) facets of TiO2. Applied Catalysis B: Environmental 2015;164:420-7.

[27] Fu M, Liao J, Dong F, Li H, Liu H. Growth of g-C3N4 Layer on Commercial TiO2 for Enhanced Visible Light Photocatalytic Activity2014.

[28] Chen Y, Huang W, He D, Situ Y, Huang H. Construction of Heterostructured g-C3N4/Ag/TiO2 Microspheres with Enhanced Photocatalysis Performance under Visible-Light Irradiation. ACS Applied Materials \& Interfaces 2014;6:14405-14.

[29] Zhang Z, Huang J, Zhang M, Yuan Q, Dong B. Ultrathin hexagonal SnS2 nanosheets coupled with $g$-C3N4 nanosheets as 2D/2D heterojunction photocatalysts toward high photocatalytic activity. Applied Catalysis B: Environmental 2015;163:298-305.

[30] Hong SJ, Lee S, Jang JS, Lee JS. Heterojunction BiVO4/WO3 electrodes for enhanced photoactivity of water oxidation. Energy \& Environmental Science 2011;4:1781-7 